\section{Fake News, \\ Citizens' Simplism and the Dangers to Democracy}

\section{Grazia Borgna}

\section{Tom Nichols}

The Death of Expertise: The Campaign

Against Established Knowledge and Why it

Matters

Oxford University Press, 2017

When we see a big family on a festive day at the restaurant and we do not hear any conversation going, but we see everybody, from grandparents to the smallest child, compulsively hacking on smart phones, we feel that a reflection is needed.

Just as when in front of the Mona Lisa we see that the majority of visitors, instead of pausing to admire her beauty, of wondering who this woman was, in what time she lived, who was the artist who portrayed her, limit themselves to a hurried selfie and away they go.

We wonder, without wanting to dramatize, how citizens, especially young people, can possibly acquire an objective, critical, but above all well-reasoned understanding of the world in which they should take part. How can they, if their vision comes mostly from the internet and social networks, contribute to the formation of a new society and get the maximum benefit from the advancing revolution? How, instead of suffering its negative effects and remaining on its margins, can they become its main actors? These and other questions are the ones Tom
Nichols, an American intellectual, posed himself observing and analyzing the evolution of the current American society in a very detailed and documented way.

In his recent book entitled "The Death of

Expertise: The Campaign Against Established Knowledge and Why it Matters", looking at the deep crisis that is engulfing American society, he tries to identify the behaviors that can aggravate it, endangering the survival of the democratic system. But he also tries to give an answer: what is necessary to do concretely to counter this dangerous involution.

He observes that, in American society, there is a new trend, in his opinion very dangerous, which, if not stopped or at least countered with force, can seriously endanger democracy. In the last fifty years, social changes have broken the old barriers of race, class and sex. But instead of producing an increase in the level of education and competence, in the United States a cultural involution has occurred whose most evident effect is a highly critical attitude, a detachment from experts, intellectuals, scientists, seen as enemies. A rejection of hierarchies and skills, an attitude present especially among the new generations.

This opposition of the "laymen" to the "experts" does not recognize the role and opinions of the latter, to which they oppose theses and solutions based on feelings and fears, rather than on real data. The importance of formal education and experience is challenged: "disinformation drives knowledge away".

Nichols states that the relationship between experts and citizens has always been based on trust. If this collapses, democracy goes into crisis. Everyone can intervene. Everyone has the right to be treated on an equal footing. Aspirations are placed in the context of a more general "rejection of inequalities". A problem that, to find a solution or at least a mitigation, must be tackled on a political level and set itself the goal to pursue, at a global level, a different 
distribution of wealth between States and, at a national level, a more equitable distribution of income.

Nichols provides many examples to support his statements.

He points out that, at the political level, the criticism of the experts was at the center of the electoral campaign which, with very devious arguments, led Trump to the presidency of the United States. A similar phenomenon occurred in the propaganda for Brexit.

At European level, Pier Cauch and André Zilberberg in a recent book on "Negationism.

Why more scientific rigor is needed in economics" (Bocconi University, Milan, 2018) reinforce Nichols's arguments with their own analyses. They note that too often we are witnessing the construction of truths not based on the results of the scientific community. They quote the false truths expressed in the electoral campaigns by Marine Le Pen, Trump, Salvini and Di Maio. They observe that, despite all of them were based on the systematic denigration of experts and on falsehood, they have become part of the political debate and are very difficult to unmask. The denigration of experts has also been at the center of other campaigns that Nichols cites. For example, those on the refusal of vaccinations, or against the consumption of eggs, or for the consumption of raw milk, and also the "conspiracy" campaigns.

These promote with arrogance questionable opinions and grotesque scenarios, as the idea that there is an elite plotting against the citizens. All those campaigns deny the data provided by scientists of the most prestigious organizations in the world, and express instead opinions that exploit fears, the return to traditions and "popular wisdom", or make use of unfounded beliefs and in some cases on opinions of experts thinking differently from the main Organizations (the most famous statements are the denial of AIDS, that climatic crises do not depend on pollution, that the earth is flat, the sun goes around the earth, the Americans have not gone to the Moon, the attack on the Twin Towers is the result of a Bush government's conspiracy, that vaccines are not necessary and can be very dangerous, that immigrants steal jobs from the natives and bring diseases, that foreign aid is a waste of money, etc.).

The fact is that the less people are competent, the less likely is for them to realize that they are wrong. Having difficulty to realize the complexity of contemporary life, citizens have increasingly less realistic expectations of what their political and economic system is in a position to offer. They are thus easy prey to the crusades against any established power (to be replaced with what?) and are defenseless in the face of data manipulation.

If search engines' information can alter the perceptions of political reality on the part of citizens, this, says Nichols, is a major problem. For example, serious dangers of vote conditioning are coming to light.

Nichols notes that some pro-Brexit politicians, after the victory, have publicly admitted that they used false data and arguments during the election campaign. But these admissions did not generate indignant reactions from voters, who tend to side uncritically in support of their "camp". An attitude which contributes to increase political polarization and to make the confrontation harsher.

These facts, in the opinion of the author, testify to the progressive decline of the cultural level of US citizens, and are closely connected with the distorted use of the new information and communication technologies. Nichols denounces the sharp increase in fake news, especially on the net. He notes that the information that is spread on the Internet on the most varied issues and problems, with no check on their reliability, have created in the citizens the illusion that they can understand, in real time, all the issues and are entitled to pass judgment even on very technical issues difficult to decode. 
The "experts of everything" tend to look on the internet and on social media for the news that confirm their beliefs, according to the irrational mechanism of the "confirmation bias". Confirmation of any idea, even wrong and dangerous. Everything becomes a matter of opinion. But "if everyone is an expert, nobody is an expert". One risks a unilateral, intransigent and dogmatic vision of reality, based on consolatory news that confirm one's own desires. A subtle trap into which refined intellectuals also fall.

This does not mean, says Nichols, that we must give absolute credit to the specialists, who are sometimes in the pay of Lobbies. A reasoned skepticism is essential not only for science but also for a healthy democracy. Experts too have made mistakes (remember Thalidomide, Vietnam, Iraq, etc.). But mistakes are rarer because on the data produced by experts, intellectuals, scientists there is an institutional control that reduces the margins of error. It is not enough to be passionate or interested, the credentials must be provided by accredited institutions that guarantee rigor with respect to the scientific community and the general public. Experts work tounderstand phenomena and produce useful generalizations, which help to decode complex situations. The laymen often produce stereotypes that should not be confused, says Nichols, with the drive towards innovation and the overcoming of old mental patterns. They are just the opposite. The conclusions they draw are based on prior judgments, therefore they accept nothing that contrasts with their vision of the world.

In the network there are also authoritative and good-quality sites belonging to study centers, Universities, Think Tanks, but there are also millions of superficial sites and fake news. There is no way to distinguish them from the others. Moreover, they are not always easy to understand, because they use a technical, difficult language.

Citizens need to have access to tools that allow them to navigate the immense universe of news that storm them 24 hours a day and that lead them to intervene in talk shows. The public debate also is strongly masterminded. Rarely based on a fair confrontation, it hosts shouting matches against those who do not share the same convictions. A dramatic show that does not aim, through an in-depth analysis and a civil confrontation, to arrive at rational conclusions.

It often happens that in such confrontations experts are confused with politicians, generating a misunderstanding about their respective roles. This confusion is misleading because while the experts, says Nichols, have the task of providing studies, statistics, research, politicians have to make decisions, that could take into account some opinions but will not necessarily share all of them.

The sense of inadequacy in the face of the complexity of contemporary life, leads citizens to the frantic search for certainties on the internet, where they can only find limited pieces of information that often generate mistrust and aversion to experts.

Nichols is convinced that this situation could represent a danger for democratic institutions, that could degenerate into a technocratic direction or into forms of power management based on the so-called digital democracy. A plebiscitary trend that would seriously endanger the liberal regimes based on Constitutions and Charters of Rights, on the division of powers and on parliamentary representation. He says that the gravity of the situation requires experts to react and make their voices heard more loudly, starting with strategic sectors such as universities and schools of journalism.

The progressive worsening of these two important sectors is one of the main causes of the incompetence of citizens, especially of young people. In contemporary journalism, the author notes, the increase in internet access and university education has come 
about at the expense of experience in the field, and has strongly contributed to a lowering of the competence level. The search for ever new fundings and striking advertisements of university offers have been winding up on themselves, contributing to both lowering the level of culture and increasing the distance between citizens and experts.

Nichols says that complaining is no longer enough to reverse the current trend. In his opinion, we need a strong reaction from those who want to counter this trend, which must start from the causes of the progressive decline of the skills of citizens, and especially of young people. The cultural downfall of both universities, the sources of knowledge, and journalism, the source of information, mustbe remedied. The current vision that reduces the cultural and educational offer to merchandise and showbiz must be fought and overcome. They are "more customers than students".

Young (under the age of thirty) people's disengagement from public issues is a very serious fact for the future of democracy. Privileging competence in university and journalism studies can contribute to generate a trend reversal. It is necessary to offer more serious, in-depth and profession-oriented studies, and to educate students to critical thinking. But we need to act simultaneously on managers, professors and journalists with regular checks on the quality of services offered and better access to continuous training.

What is needed, concludes the author, is to create a new sense of responsibility in the citizens who, should they take back their destiny and their care for public affairs, will lay the foundations for a new democracy capable of dealing with the emergencies of the $21^{\text {st }}$ century. It is necessary to overcome the gap between one's level of education and the rate at which changes in the world occur. It is a very complex operation.

This change will not happen, Nichols warns, unless a 360-degree turn, a greater assumption of responsibility will take place in people, whether simple citizens or experts. Without a collaborative attitude, open to a serious indepth analysis, a dialog between different points of view and based on mutual trust, it is not possible to fully exercise popular sovereignty, i.e. democracy.

With this book, Nichols touches very topical problems and provides data and news that help us understand them better and accept his invitation to not endure them passively, but face them. Even if the author examines above all the American situation, the thesis he supports can be applied to other realities, above all to the European Union and the whole world.

However, among his shareable arguments, which highlight important aspects of our world, some statements appear, in my view, unconvincing.

The first concerns the statement that: "the Smoot-Hawley law (which aimed at reducing the American armed forces) ... contributed to the great depression, to the collapse of the League of Nations and allowed the rise of fascism and the outbreak of the world war". It could be argued instead that it was the rise of fascism that led to the world war and the collapse of the League of Nations.

The second statement concerns the definition of the United States regime: "It is a republic, not a democracy". The author does not take into consideration the fact that the cultural decline, but above all the decline of the democratic participation of American citizens, is also attributable to the fact that the USA, which was born as a federation, is undergoing a centralization process. This is certainly one of the causes that drive citizens away from power, because it makes it difficult for them to participate in public affairs. In a federal state, instead, the distribution of competences and powers between different levels of government is a factor that promotes participation in political life. 


\section{BookReviews}

Finally, Nichols does not sufficiently emphasize the worsening of the political struggle, which at a world level some governments are pursuing, consisting in heavily interfering in the internal issues of other democratic states. Recent investigations are bringing to light the very seriousinterference put in place by, for example, the Russian Internet Research Agency based in St. Petersburg, created to unsettle Western public opinion by issuing news with a strong political impact. It intervened on social media with thousands of false news in the American, Italian and French elections, and not only to support candidates welcomed by the Russian government, but with the aim of destabilizing and inflaming the political climate to discredit pro-European and democratic political figures. 